\title{
On-Chip Dual-Band Rectangular Slot Antenna for Single-Chip Millimeter-Wave Identification Tag in Standard CMOS Technology
}

\author{
Pascal Burasa, Member, IEEE, Tarek Djerafi, Member, IEEE, Nicolas G. Constantin, Member, \\ IEEE, $\mathrm{Ke} \mathrm{Wu}$, Fellow, IEEE
}

\begin{abstract}
In this paper, an on-chip dual-band rectangular slot antenna, is proposed and demonstrated for a new generation of high data-rate, battery-free, yet active millimeter-wave identification (MMID) system, which is fully integrated on a single CMOS-die. It, therefore, does not require any external components (pad-less) nor the traditional packaging. The singleantenna solution proposed in this work addresses the overall system compactness, the cost, and the underlying technical challenges related to multi-frequency reader-tag MMID system, such as the alignment between the reader's and tag's antennas (accurate line-of-sight, especially in a short-range communication system). The targeted $24 / 40-\mathrm{GHz}$ compact antenna is a hybrid structure of a dielectric resonator antenna (DRA) and a CPW fed rectangular slot antenna in order to facilitate interconnections with other integrated circuit blocks. Design analyses of the antenna are presented. Dual dielectric resonator is optimized to enhance the antenna radiation efficiency as well as the gain over the two bands. Using a $65-\mathrm{nm}$ bulk CMOS process, a chip was fabricated and tested. The prototyped antenna exhibits a measured gain of $-1 \mathrm{dBi}$ at $24 \mathrm{GHz}$ with a bandwidth of $19 \%$, 0 dBi at $40 \mathrm{GHz}$ with a bandwidth of $20 \%$, and a radiation efficiency of $41 \%$ and $31 \%$, at $24 \mathrm{GHz}$ and $40 \mathrm{GHz}$, respectively. The antenna occupies a compact size of $2.5 \times 2.5 \times 2.5 \mathrm{~mm}^{3}$ with DRA.
\end{abstract}

Index Terms - antenna-in-package (AiP), antenna-on-chip (AoC), CMOS, dielectric resonator (DR), dual-band antenna, millimeter-wave identification (MMID), millimeter-wave RFID, packaging, system-in-package (SiP), single-chip, slot antenna.

\section{INTRODUCTION}

$\mathrm{M}$ ILLIMETER-WAVE identification (MMID) technology has recently attracted much attention in both academia and industry, essentially motivated by the anticipated applications

Manuscript received September 21, 2016. This work was supported in part by the National Science and Engineering Research Council (NSERC) of Canada and Fonds de Recherches du Québec-Nature et Technologies (FRQNT).

P. Burasa, and K. Wu are with the Poly-Grames Research Center, École Polytechnique de Montréal, Montreal, QC H3T 1J4, Canada (e-mail: pascal.burasa@polymtl.ca; ke.wu@polymtl.ca).

T. Djerafi is with the Institut National de la Recherche Scientifique, Énergie Matériaux et Télécommunications, Montréal, QC H5A 1K6, Canada (e-mail: djerafi@emt.inrs.ca).

N. G. Constantin is with the École de Technologie Supérieure, Montreal, QC H3C 1K3, Canada (e-mail: nicolas.constantin@etsmtl.ca).

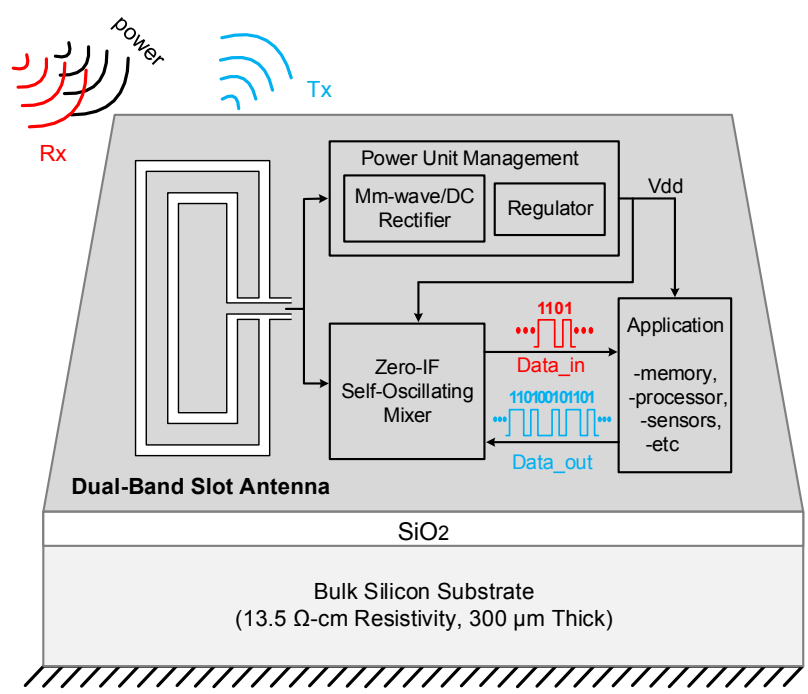

Fig. 1. Illustration of the proposed single CMOS-die active MMID tag that uses a harvested energy from an incoming $\mathrm{mmW}$ signal from the reader.

of millimeter-wave $(\mathrm{mmW})$ technology in next generation wireless communications such as $5 \mathrm{G}$ and IoT technologies, and other systems which are being developed worldwide [1], [2]. The MMID technology is emerging as a promising and future sensing technology that offers secured high-speed data communication, pinpoint sensing through steerable narrowbeam antennas, smaller tag size (over the mm-wave bands as the wavelength is comparable with IC dimensions), etc. [3].

In recent years, few works on MMID technology have been published [4]-[8]. In a recently published work [8], a 10x10 $\mathrm{mm}^{2}$ single-chip, battery-free, yet active MMID tag has been presented. The tag has experimentally demonstrated a bit rate of $500 \mathrm{kbit} / \mathrm{s}$ and $10 \mathrm{Mbit} / \mathrm{s}$ for downlink and uplink communication, respectively. However, three antennas were required to accomplish the desired tasks in the design: energy harvesting at $24 \mathrm{GHz}$, as well as data transmission and data reception, both at $40 \mathrm{GHz}$. Those off-chip antennas negatively impact the tag's sensitivity because of the packaging parasitics and transmission losses associated to the chip-to-package interconnections. This is generally less severe at lower frequencies than in the mm-wave band. Therefore, integrating antennas on the same bulk silicon substrate with other MMID tag's circuit blocks, as conceptually proposed and illustrated in 


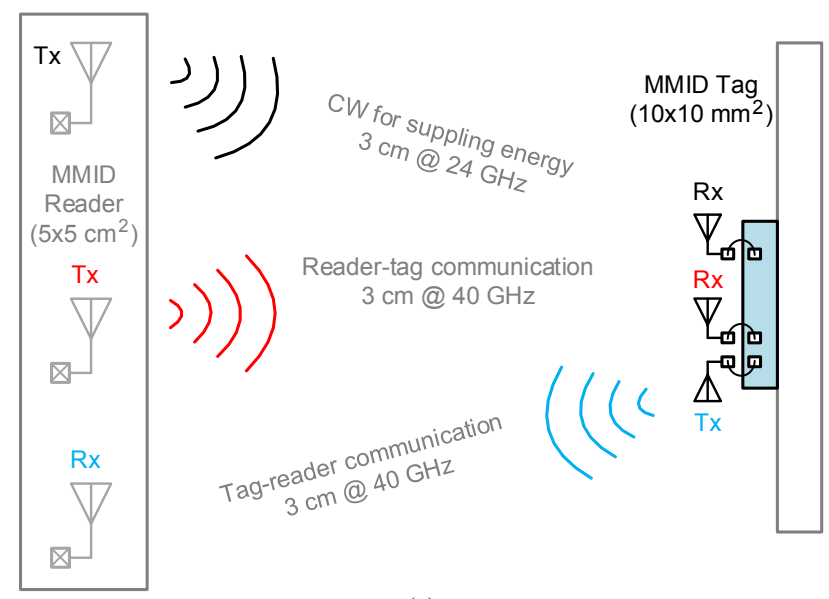

(a)

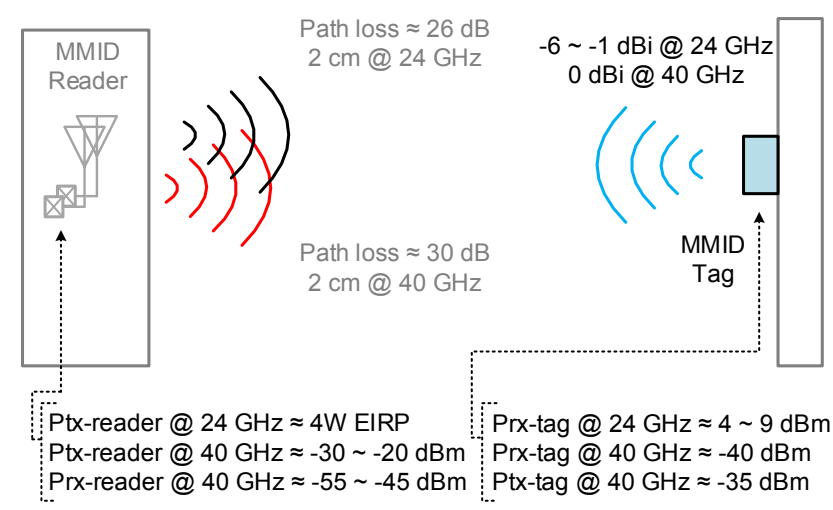

(b)

Fig. 2. Two MMID system design platforms of choice: (a) AiP-based MMID system reported in [8]; (b) AoC-based MMID system proposed in this work.

Fig.1, enables a new generation of high data-rate, fullyintegrated, and pad-less MMID tag without any external components nor packaging. To the best of our knowledge, such an MMID tag has not been reported yet.

Fig. 2 compares the antenna-in-package (AiP)-based MMID system presented in [8], with the proposed antenna-on-chip (AoC)-based system (Fig. 2(b)). In [8], a $10 \times 10 \mathrm{~mm}^{2}$ tag makes use of three different antennas with different polarizations (as illustrated in Fig. 2(a)), to wirelessly collect its energy, receive data from the reader, and transmit its data to the reader, within a communication range of about $3 \mathrm{~cm}$. The reader size is mainly dominated by three used horn antennas. Two horn antennas with a gain of $20 \mathrm{dBi}$ and an aperture of $14 \times 17 \mathrm{~mm}^{2}$ are used for both data transmission and reception at $40 \mathrm{GHz}$, and one horn antenna of $23 \mathrm{dBi}$ gain and $14 \times 17 \mathrm{~mm}^{2}$ aperture is used for power transmission at 24 $\mathrm{GHz}$, totally occupying an area of about $5 \times 5 \mathrm{~cm}^{2}$. The three horn antennas are put side by side, inclined in a non-broadside way toward the tag. However, the proposed AoC-based MMID system as depicted in Fig. 2(b) describes the fact that a single antenna in the tag as well as in the reader, with their centers aligned, translates into a wave propagation with energy more concentrated on the targeted area, hence yields a more efficient energy transfer (line-of-sight). In addition to eliminating losses associated to the physical connection between the tag and the off-chip antennas, the AoC solution enables a fully integrated MMID tag design that reduces the size and cost of the tag (which are the two obstacles to the evolution and the widespread adoption of an emerging technology).

Fig.2 (b) presents a possible link power budget for communication within a distance of about $2 \mathrm{~cm}$ between a reader and the proposed single CMOS-die tag. During the reader-to-tag communication, the tag is illuminated by two tones, namely a $24 \mathrm{GHz}$ powering signal and a $40 \mathrm{GHz}$ signal for data exchange. Assuming a 4W EIRP from the reader (a conservative analysis case since radiated power could be much higher at $24 \mathrm{GHz}$ ), the RF power received at the input of the tag is at $4 \sim 9 \mathrm{dBm}$, for which the rectifier conversion efficiency presented in [9] is at its maximum. In these conditions, about $500 \mu \mathrm{W}$ to $1.60 \mathrm{~mW} @ 1 \mathrm{~V}$ is available at the output of the rectifier, i.e. a power level which is largely above the DC power required by the tag. As illustrated in Fig.2 (b), for the tag to receive $-40 \mathrm{dBm}$ injection-locking power within $2 \mathrm{~cm} @ 40 \mathrm{GHz}$ [10], it requires the reader to transmit almost -30 to $-20 \mathrm{dBm}$, assuming 10 to $20 \mathrm{dBi}$ for the reader's transmitter/receiver antenna gain. In the other direction (tag-to-reader), with $-35 \mathrm{dBm}$ power transmitted by the tag [10], the reader receives almost -55 to $-45 \mathrm{dBm}$, assuming the same reader antenna gain. The successful implementation of such an MMID system, therefore, would require a co-centric AoC with good radiation pattern and gain performance, e.g., $\sim-6$ to $-1 \mathrm{dBi}$ at $24 \mathrm{GHz}$ and almost $0 \mathrm{dBi}$ at $40 \mathrm{GHz}$.

In this work, an AoC dual-frequency rectangular slot antenna achieving the desired gain is proposed and demonstrated. The antenna is a CPW-fed (coplanar waveguide) structure, which simplifies the integration with other system blocks. The $24-\mathrm{GHz}$ frequency goes to the integrated $\mathrm{mm}$-wave/DC rectifier and supplies energy to the tag, whereas the $40-\mathrm{GHz}$ frequency ensures a high bit-rate data exchange between the tag and the reader. The antenna is loaded with a dielectric resonator (DR) to enhance the gain and therefore the overall system efficiency.

The antenna has successfully been implemented using a commercial standard 65-nm CMOS process, and experimental results exhibit almost $-1 \mathrm{dBi} @ 24 \mathrm{GHz}$ and $0 \mathrm{dBi} @ 40 \mathrm{GHz}$, therefore supporting the feasibility of the single-chip MMID tag as proposed in this paper.

\section{ANTENNA DESIGN CONSIDERATIONS}

Different dual-frequency CMOS based systems have widely been presented in the literature as in [11] and [12]. However, most of the existing works in the literature are not related to the associated multi-frequency AoC.

Only a few dual-frequency CMOS antenna techniques are presented in the technical publications. A dual-band on-chip rectifying antenna at 35 and $94 \mathrm{GHz}$ for wireless power transmission was proposed in [13]. The LTSA (Linear Tapered Slot Antenna) rectenna is designed in slotline (SL) and finite-width ground coplanar waveguide (FGCPW) transmission lines using a $0.13 \mu \mathrm{m}$ CMOS process. The presented antenna achieves a fractional bandwidth of $82 \%$ and $41 \%$, and a gain of 7.4 and $6.5 \mathrm{dBi}$ at 35 and $94 \mathrm{GHz}$, 
respectively, with a total length of $2.9 \times 1 \mathrm{~mm}^{2}\left(0.34 \times 0.12 \lambda_{0}^{2}\right.$, considering the lower frequency point). In fact, the used LTSA is not a dual-band antenna. Instead, it is a broadband antenna, just like the whole system comprising the FGCPW and SL transition. The presented rectenna was optimized for dualband operation, using a bandpass filter added between the whole system and the rectifier.

In [14], a dual-band mm-wave CPW-fed AoC was presented for a $24 \mathrm{GHz}$ ISM band application and for $60 \mathrm{GHz}$ WPAN application. The bandwidth is about $0.75 \%$ for the lower band and about $1.67 \%$ for the second band. For the lower band, the gain is about $-9 \mathrm{dBi}$ and at the higher band, the maximum gain is about $1 \mathrm{dBi}$. The whole size is about $1.045 \times 0.76 \mathrm{~mm}^{2}\left(0.09 \times 0.06 \lambda_{0}^{2}\right.$ considering the lower frequency). In that paper, only simulated results using $0.13 \mu \mathrm{m}$ CMOS process are presented and the radiation patterns at two frequencies are not consistent. In [15], a 24/60 GHz dual-band monopole meander-line planar CMOS antenna was reported, with a gain of -3 and $-7 \mathrm{dBi}$ at 24- and $60 \mathrm{GHz}$, respectively. In fact, the reported antenna does really present a dual-band operation since the antenna responds at the third harmonic. Furthermore, the beam direction at different frequencies is incoherent, exhibiting low gain performance.

The selection of the antenna is defined principally by the feed available at chip level proposed in [8]-[10]. The rectifier circuit proposed in [9] was differentially driven, whereas the transceiver proposed in [10] uses common mode ports. To achieve dual-band characteristics in the feed with CPW, there are many reported antenna techniques and configurations. In [16], two orthogonal C-shaped monopoles are directly fed by CPW, providing a dual band $2.4 / 5.2 \mathrm{GHz}$ with spatial diversity. In [17], two operating modes of the proposed antenna are associated with various lengths of two monopoles. The proposed antenna in [18] was constructed by dual concentric annular-ring slots fabricated on FR4 substrate, using a single CPW-fed or microstrip-fed configuration. In [19], CPW can act as both a transmission line and a radiator at the same time. An extra independent frequency can be obtained without adding new components or increasing the design complexity. Two bands are necessary in our design to cover the desired tasks: energy harvesting at $24 \mathrm{GHz}$, data transmission and data reception both at $40 \mathrm{GHz}$.

The proposed antenna consists of two concentric rectangular-ring slots and the two operating frequencies are obtained by means of those multiple radiating rectangular-ring slots. The antenna is compact due to the use of the concentric ring slots, and the outer ring resonating at $24 \mathrm{GHz}$ defines the overall size. To achieve the optimal efficiency at the level of the rectifier, a DR is added to the concentric dual-band rectangular slot antenna to realize the desired gain enhancement for the MMID chip. The design parameters, rules and constraints will be detailed in the following section.

\section{A. Slot Antenna}

Although many antenna elements suitable for a CPW-fed configuration have been proposed, the slot antenna is one of the most attractive solutions. One of the main issues with $\mathrm{CPW}$-fed slot antennas is to provide an easy impedance

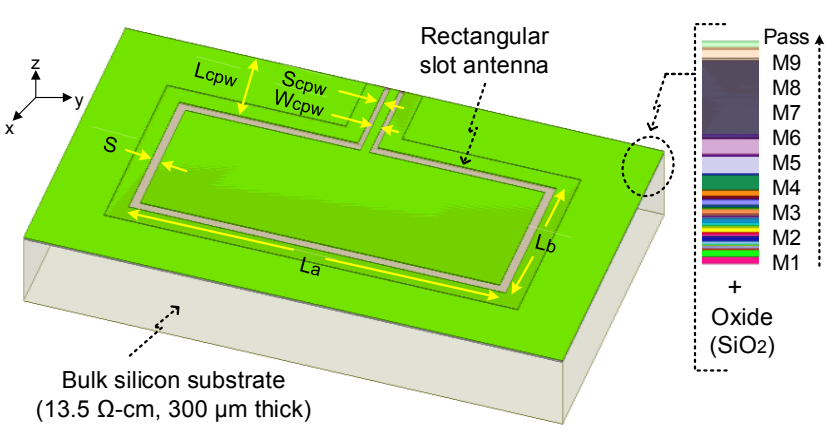

Fig. 3. Illustration of the proposed rectangular slot antenna on CMOS process.

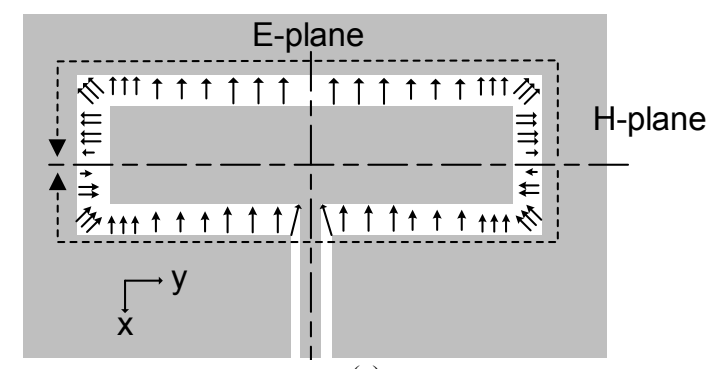

(a)

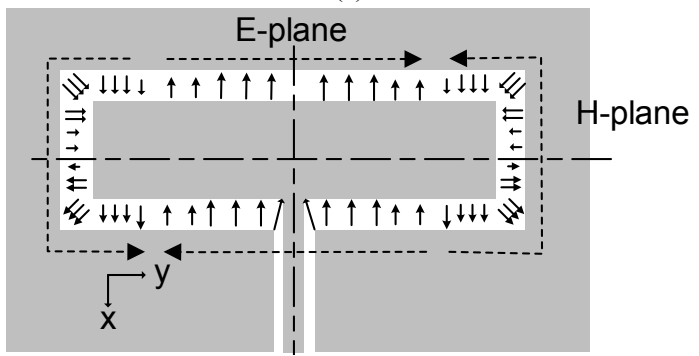

(b)

Fig. 4. Illustration of E-field field distributions in the slot region of a rectangular -ring slot antenna: (a) the first resonant mode; and (b) the second resonant mode.

matching to the CPW line. For that reason, many slot antennas using different techniques were presented in the last decade (e.g. [20]-[23]).

Different slot antennas using CMOS technology have been reported. A novel design for a fully on-chip antenna operating at $140 \mathrm{GHz}$ was proposed in [24]. In addition to a traditional microstrip feeding, the slot antenna is backed with an extremely thin cavity formed by two CMOS inner metal layers and vias in between. The simulated gain is around $2 \mathrm{dBi}$. The total area of this antenna is $1.2 \times 0.6 \mathrm{~mm}\left(0.09 \times 0.06 \lambda_{0}{ }^{2}\right.$ at 140 $\mathrm{GHz})$. In [25], a $60 \mathrm{GHz}$ slot AoC was designed on a CMOS substrate. To enhance the slot AoC performance, an off-chip artificial dielectric layer (ADL) which is known for its anisotropic properties was designed using UL2000 substrate. Gain and efficiency at $60 \mathrm{GHz}$ are $3.6 \mathrm{dBi}$ and $32.5 \%$, respectively. A folded dipole slot antenna backed by artificial magnetic conductor (AMC) structure based on a standard 0.18 um CMOS process was proposed in [26] at $140 \mathrm{GHz}$. An AMC constructed by a periodic $6 \times 6$ square patch array is adopted as the background to improve the gain of the proposed folded dipole slot to $-2 \mathrm{dBi}$.

Rectangular slot-ring antennas are designed in our work, using CPW feed lines. The rules defined in [23] are used to 


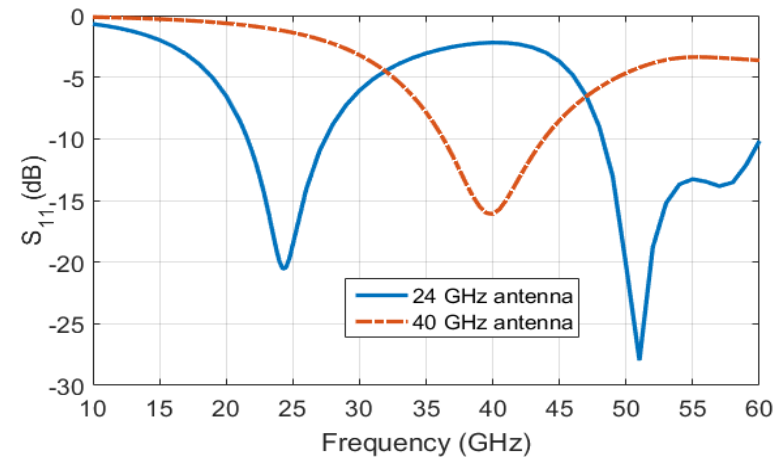

Fig. 5. Reflection coefficient $|\mathrm{S} 11|(\mathrm{dB})$ of the rectangular slot antennas at $24 \mathrm{GHz}\left(L_{a}=1.78 \mathrm{~mm}, L_{b}=0.89 \mathrm{~mm}, \mathrm{~S}=0.04 \mathrm{~mm}, \mathrm{~W}_{\mathrm{CPW}}=0.05 \mathrm{~mm}, \mathrm{~S}_{\mathrm{CPW}}=\right.$ $\left.0.02 \mathrm{~mm}, \mathrm{~L}_{\mathrm{CPW}}=0.16 \mathrm{~mm}\right)$ and $40 \mathrm{GHz}\left(L_{a}=1.32 \mathrm{~mm}, L_{b}=0.43 \mathrm{~mm}\right.$, $\left.\mathrm{S}=0.04 \mathrm{~mm}, \mathrm{~W}_{\mathrm{CPW}}=0.05 \mathrm{~mm}, \mathrm{~S}_{\mathrm{CPW}}=0.02 \mathrm{~mm}, \mathrm{~L}_{\mathrm{CPW}}=0.39 \mathrm{~mm}\right)$.
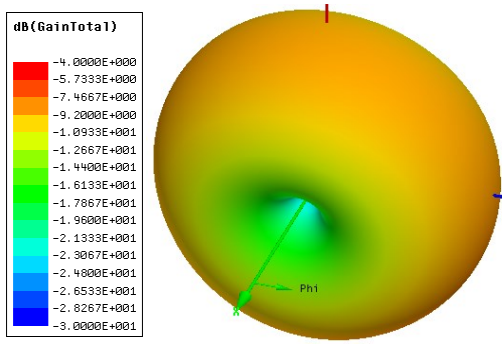

(a)

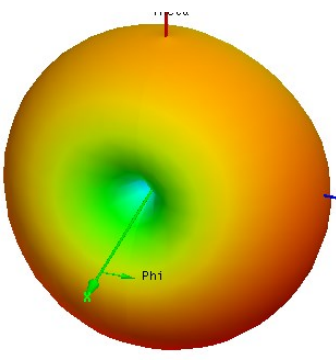

(b)
Fig. 6. Simulated 3D radiation patterns of the dual-band rectangular slot antenna: (a) $24 \mathrm{GHz}$, (b) $40 \mathrm{GHz}$.

design the slot ring. The resonant frequencies of both antennas are primarily determined by the mean perimeter of their respective rectangular-ring slots. The initial slot width is selected to be around $\lambda_{\mathrm{r}} / 10$ ( $\lambda_{\mathrm{r}}$ : wavelength) to avoid the appearance of a leaky-wave mode.

Fig .3 illustrates the proposed configuration for the on-chip slot antenna, which consists of a rectangular slot aperture with slot width S, length $L_{a}$ and width $L_{b}$, implemented on the top metal layer (M9) and above a silicon dioxide $\left(\mathrm{SiO}_{2}\right)$ dielectric, between the top most metal layer (M9) and bottom metal layer (M1). The $\mathrm{SiO}_{2}$ dielectric is therefore only around $5.5 \mu \mathrm{m}$, given the spacing between M1 and M9 in a typical CMOS chip. The $300 \mu \mathrm{m}$ bulk silicon substrate has a low resistivity $(13.5 \Omega-\mathrm{cm})$. The antenna is fed from the edge by a $50-\mathrm{ohm}$ CPW line $\left(W_{c p w}, S_{C P W}\right)$. The dimensions are selected to have a resonance frequency at:

$$
c /\left(2\left(\mathrm{~L}_{\mathrm{a}}+\mathrm{L}_{\mathrm{b}}\right) \sqrt{\varepsilon_{\text {eff }}}\right)
$$

with $\mathrm{c}$ being the speed of light in free space, and $\varepsilon_{\text {eff }}$ the effective dielectric constant for a slotline. To avoid a very low radiation efficiency, the bottom metal layer (M1) is generally not used as ground shielding between the insulator layers and the silicon substrate [27]. With the CPW structure, a large part of electromagnetic fields is directed in the air above the top metal layer. However, not using the bottom metal layer (M1) allows the antenna radiating more toward the low resistivity, high permittivity silicon substrate than if M1 were present, which translates into a severe degradation of gain and efficiency at mm-wave frequencies [28].

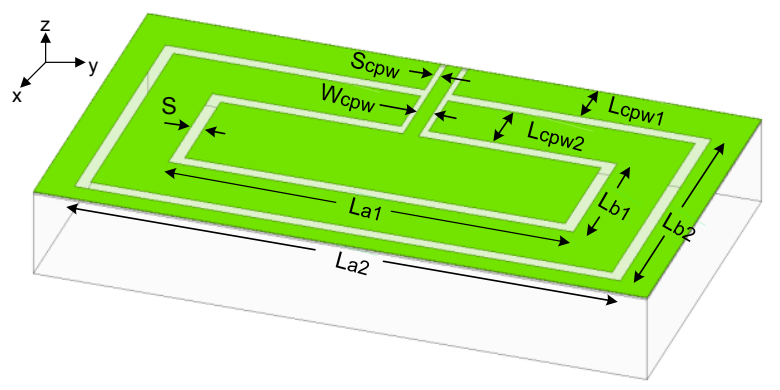

Fig. 7. Illustration of the proposed dual-band rectangular slot antenna on CMOS process.

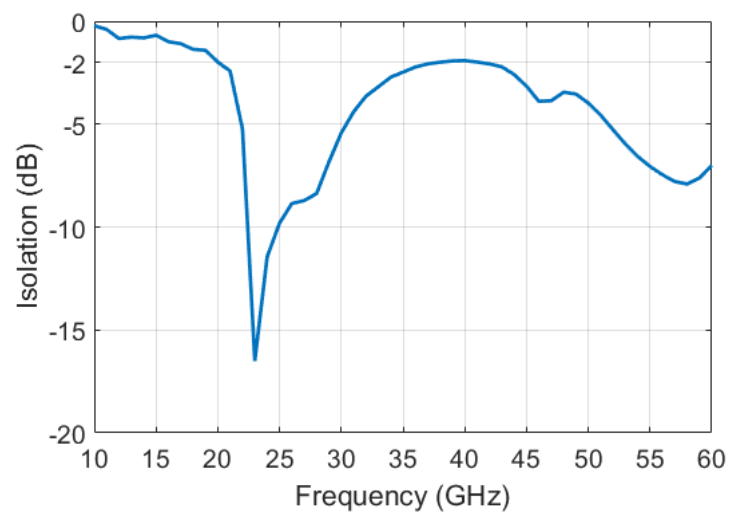

Fig. 8. Transmission from the common input port to the $40 \mathrm{GHz}$ rectangular slot.

Fig 4 illustrates the first and second resonant-mode equivalent electric field distributions of the rectangular ring slot antenna, which were sketched according to the results simulated using Ansoft High Frequency Structure Simulator $\left(\mathrm{HFSS}^{\mathrm{TM}}\right)$. The half-guided-wavelength routes of the magnetic currents are denoted by the short-dashed lines drawn beside the magnetic-current distributions. For the first resonant mode, the lower-side half-guided-wavelength route is slightly shorter than the upper-side one because of the shunt capacitance introduced by the feeding line.

As evidenced by the electric field distribution shown in Fig. 4(a), the horizontal electric field distribution is asymmetrical. However, the vertical electric field distribution is symmetrical along the horizontal direction. As a result, the rectangular ring slot antenna is linearly polarized. The E and H-planes are defined in Fig. 4. For the second resonant mode, there exist four half-wavelength routes for the magnetic currents, among which the one passing the feeding position has the shortest length. As shown by the electrical field distribution, it is identical in terms of orientation to that in the first mode.

To validate the design, S-parameters of the proposed antennas (24 and $40 \mathrm{GHz}$ ) were simulated using Ansoft HFSS, as shown in Fig. 5. The bandwidths for a $10-\mathrm{dB}$ reflection coefficient are $5.86 \mathrm{GHz}(18.19 \%)$ for the $24 \mathrm{GHz}$ band and $11.87 \mathrm{GHz}(21.29 \%)$ around the corresponding harmonic frequency $(48 \mathrm{GHz})$. However, a resonance around $57 \mathrm{GHz}$ appears, corresponding to the resonance of the dipole slot antenna with a CPW-fed structure and $L_{a}$ arm (as illustrated in Fig. 4(a)). The desired stop-band for this first antenna clearly appears around $40 \mathrm{GHz}$. For the second antenna, designed at $40 \mathrm{GHz}$, the bandwidth for a $10-\mathrm{dB}$ reflection coefficient is 


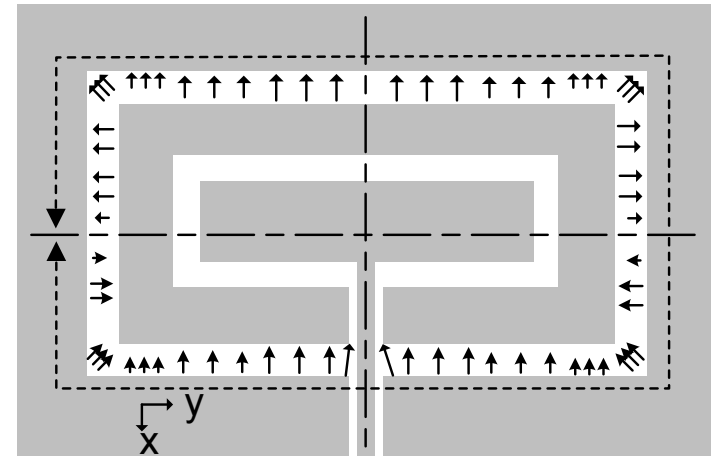

(a)

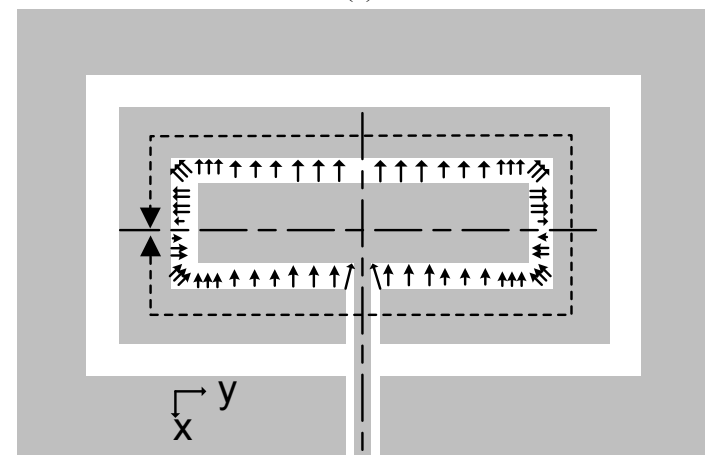

(b)

Fig. 9. E-field field distributions in the slot region of a rectangular slot antenna: (a) the first resonant mode; and (b) the second resonant mode.

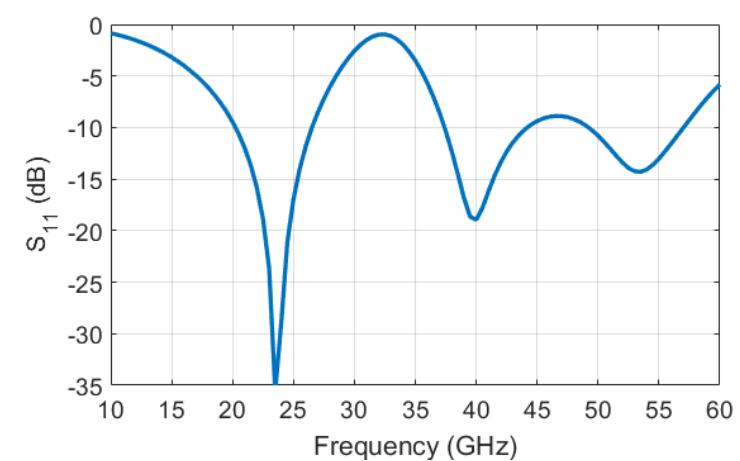

Fig. 10. Reflection coefficient $|\mathrm{S} 11|(\mathrm{dB})$ of the dual-band rectangular slot antenna $\left(L_{a 1}=1.78 \mathrm{~mm}, L_{b 1}=0.89 \mathrm{~mm}, L_{a 2}=1.32 \mathrm{~mm}, L_{b 2}=0.43 \mathrm{~mm}, S=0.04\right.$ $\left.\mathrm{mm}, W_{C P W}=0.05 \mathrm{~mm}, \mathrm{~S}_{\mathrm{CPW}}=0.02 \mathrm{~mm}, L_{C P W 1}=0.16 \mathrm{~mm}, L_{C P W 2}=0.19 \mathrm{~mm}\right)$.

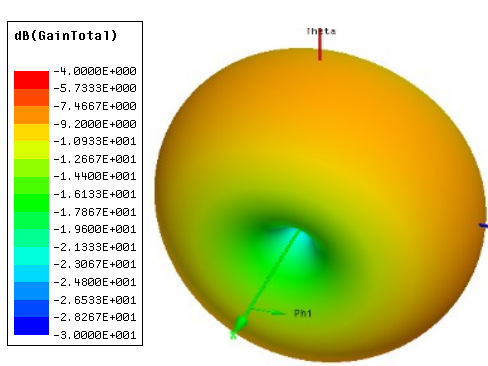

(a)

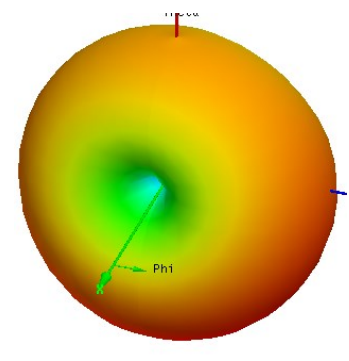

(b)
Fig. 11. Simulated 3D radiation patterns of the dual-band rectangular slot antenna: (a) $24 \mathrm{GHz}$, (b) $40 \mathrm{GHz}$.

7.56 GHz (21.29\%). These results suggest that the proposed antenna has exceptional quality factors and selectivity. The antennas cover the desired bandwidths around the two frequencies. The selectivity for each one may be increased by reducing their respective slot width $S$ (as depicted in Fig. 3).

The $3 \mathrm{D}$ radiation patterns of the proposed antennas are shown in Fig. 6. For the $24 \mathrm{GHz}$ antenna, the radiation in the E-plane ( $x z$ plane) is quasi-isotropic with a variation of $2 \mathrm{~dB}$ in the level ( $2 \mathrm{~dB}$ of cross-polarization level) achieving $-8 \mathrm{dBi}$ of gain. The $3-\mathrm{dB}$ beam width over the H-plane ( $y z$ plane) is about 65 degree. For the $40 \mathrm{GHz}$ antenna, the $3-\mathrm{dB}$ beam widths are 360 (quasi-isotropic) and 60 degree in the E-plane ( $x z$ plane) and H-plane ( $y z$ plane). For the $40 \mathrm{GHz}$ antenna, the cross-polarization level is about $20 \mathrm{~dB}$ with a gain of $-5 \mathrm{dBi}$. The two frequencies share a very similar pattern with different gain (the same gain aperture efficiency) and they have the same polarization planes.

\section{B. Dual-Frequency Co-Centered Slot Antenna}

The geometries of the proposed CPW-fed dual-frequency rectangular-ring slot antennas are shown in Fig. 7. The outer slot loop perimeter is used to fix the operating lower frequency and the inner one fixes the higher band.

By adjusting the widths of the slots and the length of the arm, at the first band $(24 \mathrm{GHz})$ all the energy is radiated. At the higher band $(40 \mathrm{GHz})$ the energy is directed to the inner loop of the proposed antenna. As demonstrated in Fig. 8, the energy from the external port to a virtual port defined at the input of the inner rectangular slot is small at $24 \mathrm{GHz}$, whereas the same figure indicates a coupling of $2 \mathrm{~dB}$ at $40 \mathrm{GHz}$. This demonstrates a good isolation of the $24 \mathrm{GHz}$ antenna from a $40 \mathrm{GHz}$ excitation at the external port, necessary for a dualband operation. (Losses at this frequency represent $80 \%$ of this value). It implies also that both antennas can be excited with a good impedance matching. Moreover, a small shift of both resonant frequencies (e.g. $21.5 \mathrm{GHz}$ instead of $24 \mathrm{GHz}$, as indicated from Fig. 8) is justified by the interaction between the two slots.

Fig. 9 shows a sketched representation of the electric-field distribution for the $\mathrm{CPW}$-fed dual-frequency rectangular-ring slot antenna, based on HFSS simulation results. Using this electromagnetic simulator, design parameters for both antennas were optimized. Since each resonant point relates to one parameter exclusively, parameters for each rectangular slot are optimized at a time to place the two frequencies at the anticipated points to meet different requirements. In the last steps, adjusting the frequencies and matching the input impedance were achieved by the tuning of the width of the two slots.

To validate the design procedure, S-parameters of the proposed antenna were simulated with HFSS. The bandwidths for a $10-\mathrm{dB}$ reflection coefficient are $6.3 \mathrm{GHz}(15.42 \%)$ and $6.8 \mathrm{GHz}(16.6 \%)$ for the $24 \mathrm{GHz}$ and $40 \mathrm{GHz}$ antennas respectively, as shown in Fig 10.

The radiation patterns of the proposed antenna are shown in Fig. 11 for the two frequencies. The gain, the $3-\mathrm{dB}$ beam widths in the E-plane ( $x z$ plane) and H-plane ( $y z$ plane) are almost the same as in the case of the two separate antennas, with a small reduction in the case of the $24 \mathrm{GHz}$ antenna. To obtain the proper resonance frequencies, the areas were reduced, while the perimeters were kept constant. The cross- 


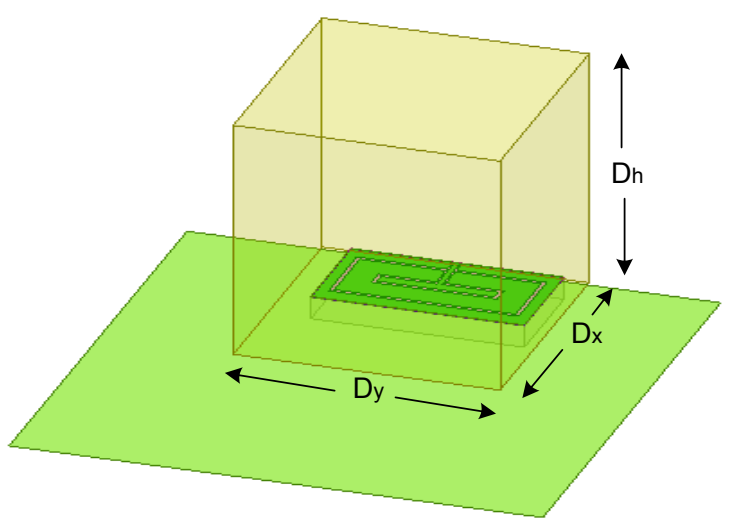

Fig. 12. Geometry of the proposed DRA.

polarization level is about 38 and $25 \mathrm{~dB}$ for the $24 \mathrm{GHz}$ and 40 $\mathrm{GHz}$ bands, respectively.

\section{DRA-LOADED, DUAL FREQUENCY, CO-CENTERED SLOT ANTENNA}

The gain achieved by the dual-frequency antenna is not sufficient to cover the required MMID functionalities and ranges. A gain enhancement mechanism should be used to overcome this limit. Different off-chip gain enhancement

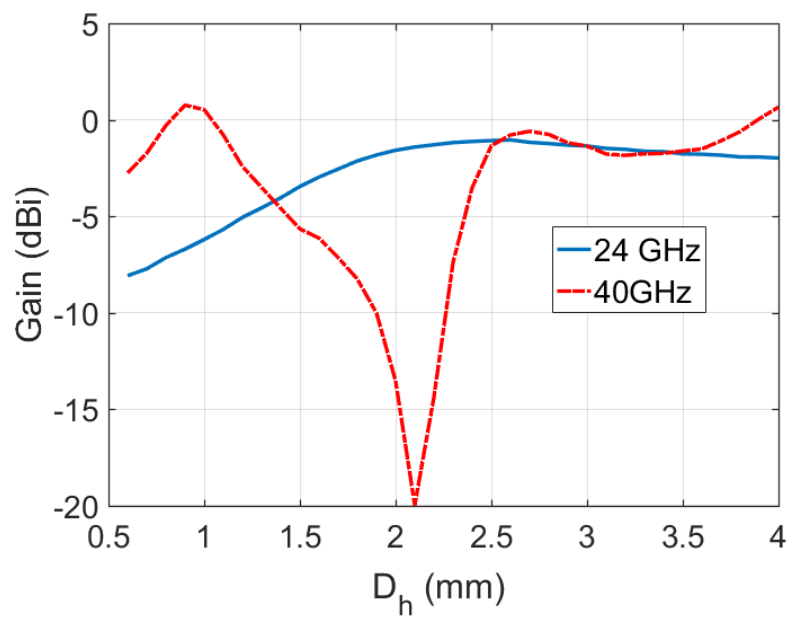

Fig. 13a. Gain .vs. DR thickness $D_{h}\left(D_{\mathrm{x}}=2 \mathrm{~mm}, D_{\mathrm{y}}=2 \mathrm{~mm}\right)$.

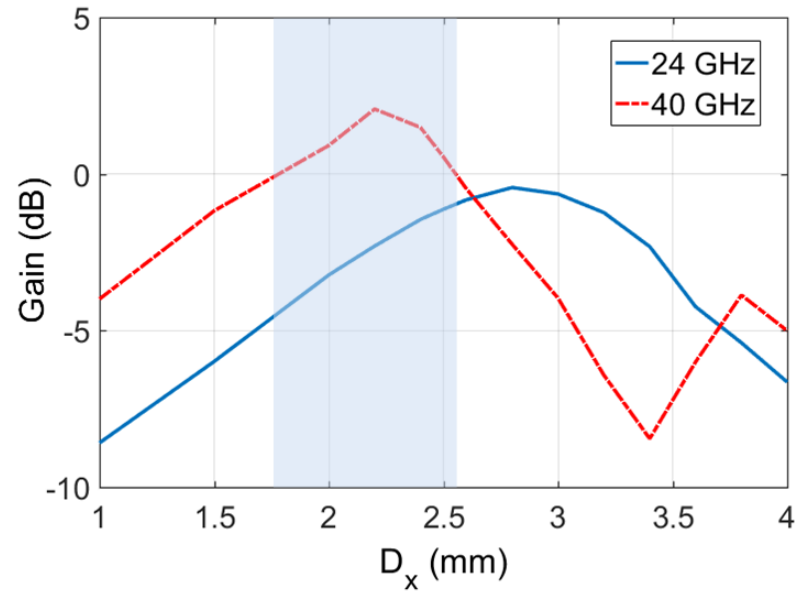

Fig. 13b. Gain .vs. DR dimension $D_{x}\left(D_{\mathrm{h}}=100 \mathrm{mil}, D_{\mathrm{y}}=2 \mathrm{~mm}\right)$. methods combined with CMOS antennas have been proposed in the literature, for example, artificial dielectric layer (ADL) in [25] and stacked dielectric resonators (DRs) in [29] or lens as in [30]. These techniques are used for gain enhancement in the range of about $10 \mathrm{~dB}$ and also improve efficiency and bandwidth. The DR mechanism is selected due to its convenient fabrication and integration and also the availability of its related processing technique in our laboratory.

Several investigations have been reported on DRAs with dual-frequency operation using various methods [31]-[33]. Dual-band dielectric resonator antenna (DRA) using a parasitic C-slot fed by a microstrip line was proposed in [31]. Dual-band and wideband features are achieved based on a modified Sierpinski gasket [32], and in [33] DRA was placed on top of a slotted cavity to form a hybrid dual-band antenna. A slight degradation of the radiation pattern caused by higher modes was observed.

Our proposed technique combines a slot antenna and a dielectric resonator antenna (DRA) to effectively increase the gain without compromising miniaturization, nor efficiency. In our DR-slot hybrid antenna structure, the two radiating resonators (DRA and rectangular slot resonator) are tightly

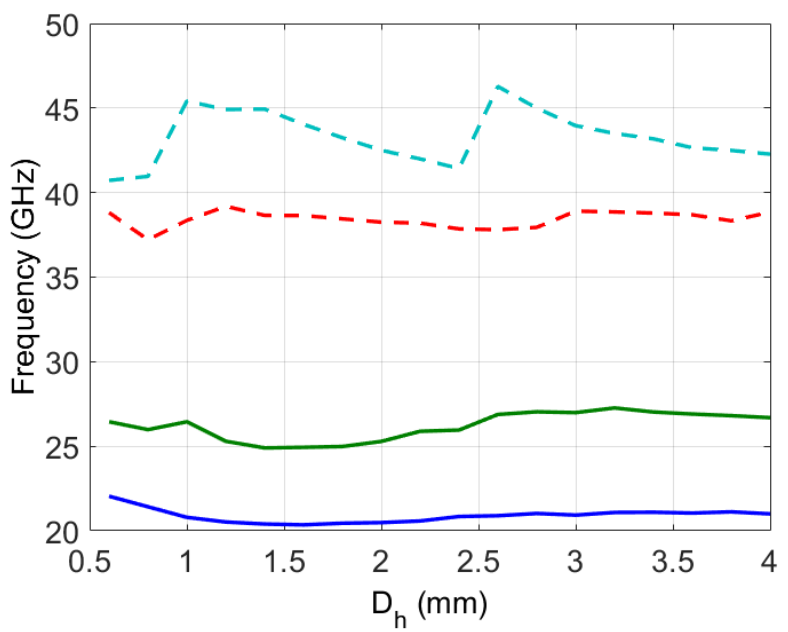

(a)

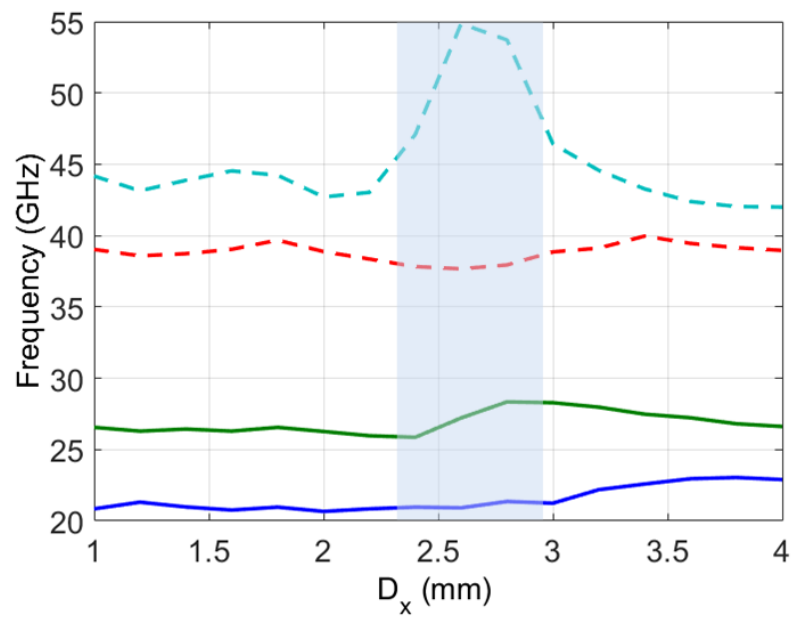

(b)

Fig. 14. Effect of DRA dimensions on the 10-dB impedance bandwidths: (a) DR dimension $D_{h}$, (b) DR dimension $D_{x}$. 


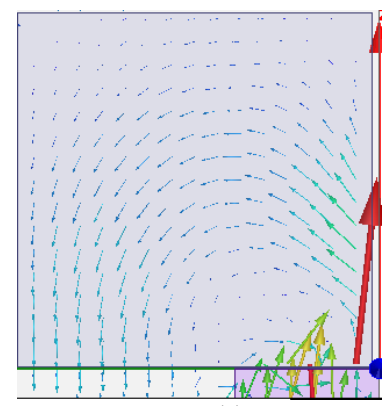

(a)

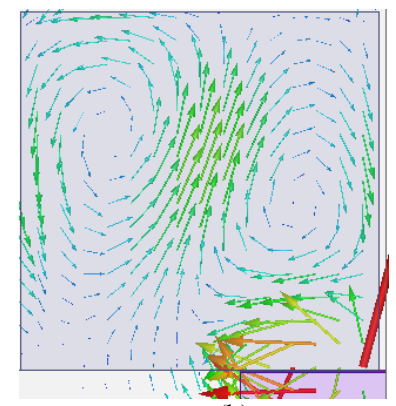

(b)

Fig. 15. Electric field distribution of the proposed antenna: (a) $24 \mathrm{GHz}$, (b) $40 \mathrm{GHz}$.

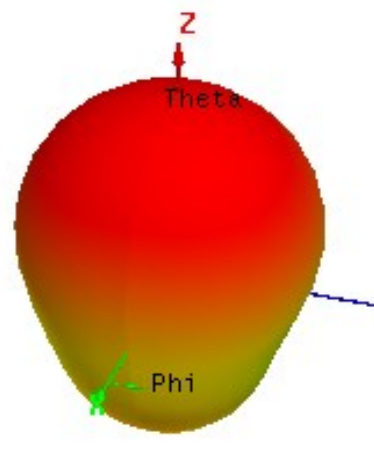

(a)

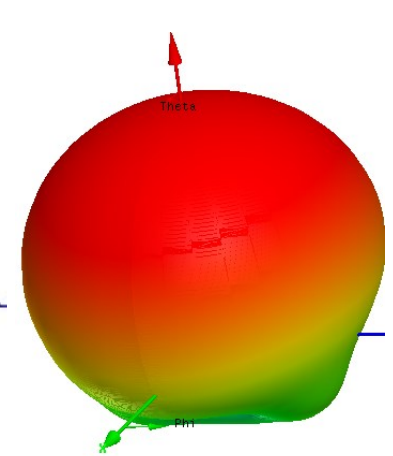

(b)
Fig. 16. Simulated 3D radiation patterns o the dual-band rectangular slot antenna with DRA: (a) $24 \mathrm{GHz}$, (b) $40 \mathrm{GHz}$.

stacked together, offering more flexibility and direct compatiblity with different mounting surfaces.

As shown in Fig. 12, a rectangular dielectric resonator antenna of dimensions $D_{x} \mathrm{x} D_{y} \mathrm{x} D_{h}$ is placed on a large metallic (PEC) ground plane. The high relative permittivity material $\varepsilon_{\mathrm{r}}=9.6$ is used. Mainly, this high permittivity substrate reduces the effect of the bulk silicon substrate on the gain. The coupling level can be adjusted through the positioning of the DRA above the slot antenna ring. The coupling behavior of the slot ring is similar to that of the coaxial probe, but the rectangular slot antenna structure offers the advantage of being nonobtrusive [34]. The dielectric block is generally centered on the coupling slot, and the slot centered above the under-passing microstrip feed line as in [34] and [35]. In [36], a slot-coupled rectangular DRA design was presented, wherein the dielectric resonator has a square base, but it is markedly offset with respect to the coupling slot. The dualband rectangular slot used allows a coupling of the field to the DRA mode in a non-centered configuration (offset in $x$ direction).

A rectangular DR is selected since the three independent dimensions offer more flexibilities. $\mathrm{D}_{\mathrm{y}}$ is selected to cover the width of the ring $\left(>L_{\mathrm{a}}\right)$. A parametric study for the two other parameters was carried out to optimize the antenna in order to achieve desired reflection coefficients, radiation patterns, and gains of the dual-band antenna.

As shown in Fig. 13 (a), the peak of the gain for the 24 $\mathrm{GHz}$ band is achieved with a thickness $D_{\mathrm{h}}=2.5 \mathrm{~mm}$. For the 40 $\mathrm{GHz}$ band, the gain peak is achieved with $D_{h}$ around 1 . In both cases, the probe is exciting the $\mathrm{TE}_{111}$ fundamental mode of the rectangular DRA. At $\mathrm{D}_{h}=2.75 \mathrm{~mm}$, the $40 \mathrm{GHz}$ antenna shows another gain maximum. The effect of parameter $D_{x}$ on the gain is plotted in Fig. 13 (b). For the $24 \mathrm{GHz}$ band, the gain reaches the maximum at $D_{x}=2.75 \mathrm{~mm}$ and for the $40 \mathrm{GHz}$ band at

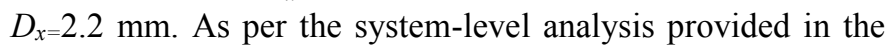
Introduction section, a $0 \mathrm{dBi}$ gain is required at $40 \mathrm{GHz}$, while there is a more flexibility at $24 \mathrm{GHz}$, (i.e. from -6 to $-1 \mathrm{dBi}$ ).

Fig. 14 shows the lower and upper frequencies of the $10 \mathrm{~dB}$ impedance bandwidth of the two bands as functions of $D_{\mathrm{h}}$ and $D_{\mathrm{x}}$. From the figure, it is observed that the DRA mode appears at the two bands when $D_{\mathrm{h}}=2.6 \mathrm{~mm}$ and the $10 \mathrm{~dB}$ bandwidth increases with $D_{x}$ between 2.5 and $3 \mathrm{~mm}$. Outside this region, the DR does not affect the frequency significantly and the slot mode is preponderant. The DR thickness is selected to be 120 mil $(3 \mathrm{~mm})$ due to the availability of ceramic substrates, and the gray zone in Fig. 13 (b) and Fig 14 (b) defines a possible tradeoff to achieve the two constraints of gain and bandwidth.

The inner electric field distributions for the two resonant frequencies are illustrated in Fig.15. The TE111-like mode of the full-size DR is excited at the lower frequency of $24 \mathrm{GHz}$. Fig.15 (b) shows that a TE121-like mode, which operates at a frequency close to the upper band at $40 \mathrm{GHz}$, and is attributed to the full-size DR physical and electrical characteristics.

The radiation patterns of the proposed antenna are shown in Fig. 16. Clearly, the proposed antenna transfers from omnidirectional radiation to unidirectional radiation. As these results also show, with the addition of the DRA, the peak gain increases from $-8 \mathrm{dBi}$ to $0 \mathrm{dBi}$ in the $24 \mathrm{GHz}$ band, and to $1 \mathrm{dBi}$ in the $40 \mathrm{GHz}$ band. The front-to-back ratio is about 10 $\mathrm{dB}$ and $18 \mathrm{~dB}$, respectively, and the cross polarization at 50 $\mathrm{dB}$.

\section{ANTENNA MEASUREMENTS}

The antenna prototype was fabricated using a standard 65$\mathrm{nm}$ bulk CMOS process and tested to validate the antenna properties. The antenna has an area of $2 \times 1 \mathrm{~mm}^{2}$ including the bond pads. Unlike other proposed on-chip antennas where measurements are generally carried out on-wafer, Fig.17 (a) shows our measurement setup, intended for measurements with a complete test assembly. The on-chip antenna under test is mounted on a PCB to allow characterizing the antenna using a network analyzer in our anechoic chamber. A K-connector interfaces with a $50 \mathrm{Ohm}$ microstrip line which is connected to the antenna through a bonding wire. The combination of the $\mathrm{K}$-connector, the microstrip line, and the bonding wire has been accurately modelled through an EM simulation (HFSS ${ }^{\mathrm{TM}}$ ) to make sure that their impact on the antenna performances is negligible. Accurate and simple bonding wire models have been extensively studied and reported up to 100 $\mathrm{GHz}$ [37] and [38], and previous works have demonstrated antennas connected through bonding wires performing quite well at $60 \mathrm{GHz}$ [39], [40]. In [40], for example, a CPW and a bonding wire are used (even preferable) between the antenna and the probes in order to avoid the impact of probe tips on the antenna at $67 \mathrm{GHz}$. The bonding wires have been realized in our Poly-Grames Research Center which has presented an excellent track record even up to $60 \mathrm{GHz}$ [41], [8]. 


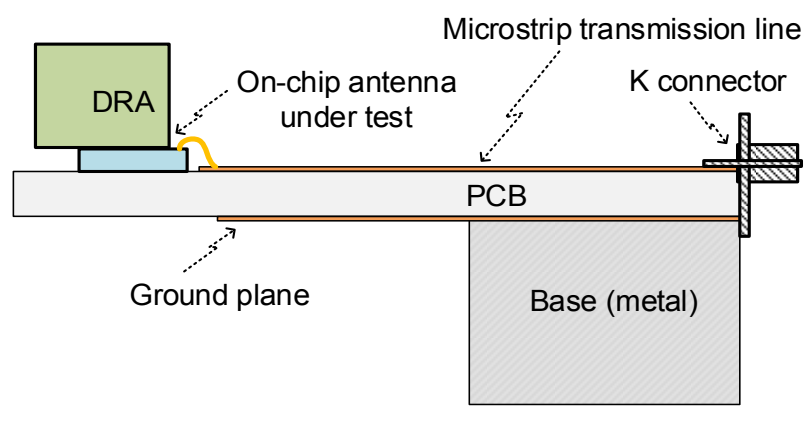

(a)

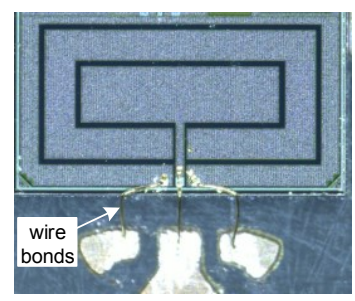

(b)

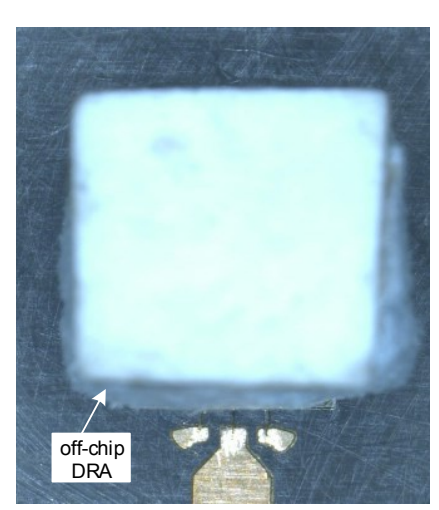

(c)

Fig. 17. Radiation measurement setup of the fabricated on-chip dual-band slot antenna $\left(L_{a}=1.54 \mathrm{~mm}, L_{b}=0.76 \mathrm{~mm}, \mathrm{~S}=0.03 \mathrm{~mm}, \mathrm{~W}_{\mathrm{CPW}}=0.05 \mathrm{~mm}\right.$, $\left.\mathrm{S}_{\mathrm{CPW}}=0.02 \mathrm{~mm}, \mathrm{~L}_{\mathrm{CPW}}=0.16 \mathrm{~mm}\right)$ and $40 \mathrm{GHz}\left(L_{a}=1.02 \mathrm{~mm}, L_{b}=0.25 \mathrm{~mm}\right.$, $\mathrm{S}=0.03 \mathrm{~mm}, \mathrm{~W}_{\mathrm{CPW}}=0.05 \mathrm{~mm}, \mathrm{~S}_{\mathrm{CPW}}=0.02 \mathrm{~mm}, \mathrm{~L}_{\mathrm{CPW}}=0.39 \mathrm{~mm}$ ) (a) block diagram; (b) die microphotograph of the fabricated antenna without DR; (c) antenna with DR.

The DR is manually mounted on the chip using nonconductive epoxy glue, with a careful alignment thanks to reference marks on the PCB. The PCB and the on-chip antenna are supported by a metallic base and, to minimize the effect of this metallic base, the antenna is mounted at $7 \mathrm{~mm}$ away from it. Fig. 17(b) and (c) show the microphotograph of the fabricated antenna with and without DR, respectively. The resonator has dimensions $2.5 \times 2.5 \times 2.5 \mathrm{~mm}^{3}$ on a square metallic ground plane of dimensions $5 \mathrm{~mm} \times 5 \mathrm{~mm}$. Underneath the ground plane is a thin dielectric substrate of relative permittivity $\varepsilon_{\mathrm{r}}=2.9$ and thickness $\mathrm{d}=0.5 \mathrm{~mm}$.

Simulated and measured loss values of the proposed antenna are plotted versus frequency in Fig. 18. The simulated results take into consideration only the on-chip antenna, as opposed to the measured results which include the on-chip antenna, bonding wires, microstrip line (the PCB process), and the $\mathrm{K}$-connector as well. It is observed that the antenna resonates at two distinct frequencies, 24 and $40 \mathrm{GHz}$ with bandwidths of $23 \%(20.5-25.5 \mathrm{GHz})$ and $17 \%(38-45 \mathrm{GHz})$, respectively. Small shifts are observed at $24 \mathrm{GHz}$ (down) and at $40 \mathrm{GHz}$ (up). Note that the K-connector used is intended for measurements up to $40 \mathrm{GHz}$, whereas our measurements extend to beyond $45 \mathrm{GHz}$. The resonances appeared at different frequencies in the measurements are due principally to bonding wire and the whole experimental setup.

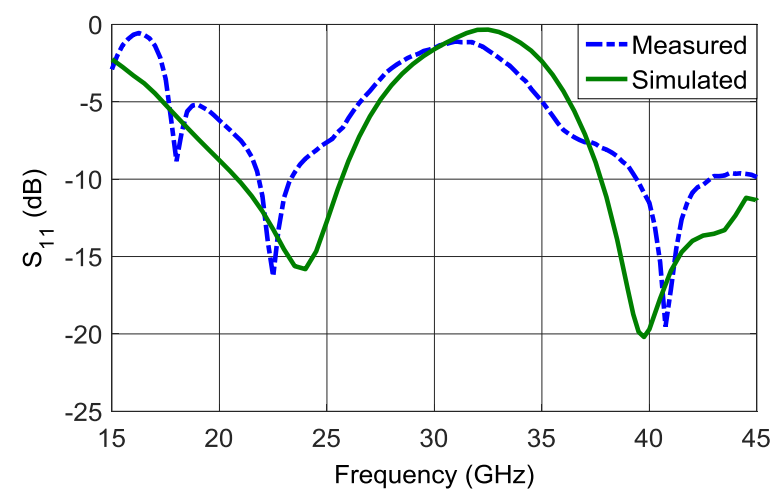

Fig. 18. Reflection coefficient $\left|\mathrm{S}_{11}\right|(\mathrm{dB})$ of the antenna (simulated and measured).

The radiation patterns of the proposed antenna are shown in Fig. 19. Simulated and measured radiating results are quite similar, and show that the antenna radiation patterns are successfully converted from omnidirectional-like radiation to unidirectional radiation, as explained in the preceding section. For the $24 \mathrm{GHz}$ resonance, the $3-\mathrm{dB}$ beam widths are 120 and 65 degree in the E-plane ( $x z$ plane) and H-plane ( $y z$ plane) measurements and 90 and 50 degree in the measured counterparts. For the $40 \mathrm{GHz}$ resonance, the simulated 3-dB beamwidth are 90 and 80 degree in the E-plane ( $y z$ plane) and H-plane ( $x z$ plane), respectively $(74$ and 80 in the measurement). The measured radiation patterns are not as symmetric as the simulated ones, with a small shift in the 0 degree direction especially for the $24 \mathrm{GHz}$ frequency. The measured peak gain is about $-1 \mathrm{dBi}$ for the $24 \mathrm{GHz}$ band, and in the $40 \mathrm{GHz}$ band, the antenna peak gain is about $0 \mathrm{dBi}$. Besides, Front-to-Back Ratio (FBR) at $24 \mathrm{GHz}$ is enhanced from $10.4 \mathrm{~dB}$ to $17.5 \mathrm{~dB}$ as shown in the simulation. Our anechoic chamber facility covers from -90 to 90 degree.

\section{CONCLUSION}

In this paper, an on-chip dual-frequency rectangular slot antenna, suitable for a self-powered, single-chip, active MMID tag has been proposed and demonstrated. The antenna was implemented using a 65-nm standard CMOS technology. In addition to a thoughtful design, analysis and optimization, the DRA sizing and the location of the feeding point are identified as key factors that enhance the radiation efficiency and the gain in both frequency bands of interest. The proposed on-chip antenna achieves a measured gain of $-1 \mathrm{dBi}$ at $24 \mathrm{GHz}$ with a bandwidth of $19 \%, 0 \mathrm{dBi}$ at $40 \mathrm{GHz}$ with a bandwidth of $20 \%$, and a radiation efficiency of $41 \%$ and $31 \%$, at 24 $\mathrm{GHz}$ and $40 \mathrm{GHz}$, respectively. This supports and contributes to demonstrating the feasibility of a single CMOS-die MMID tag solution proposed in this work (Fig. 1).

\section{ACKNOWLEDGMENT}

The authors would like to thank CMC Microsystems, Kingston, ON, Canada, for their technical support, design 


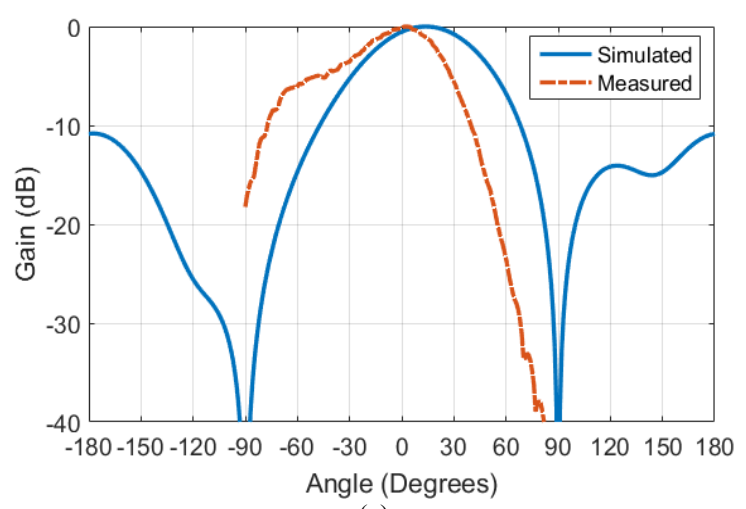

(a)

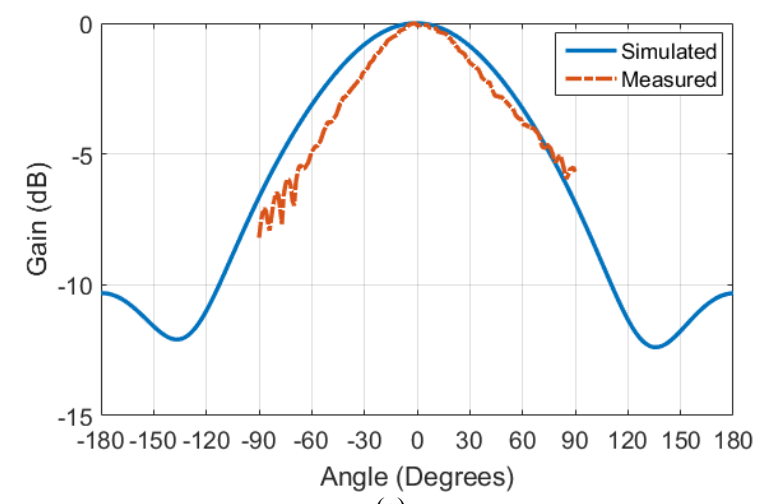

(c)

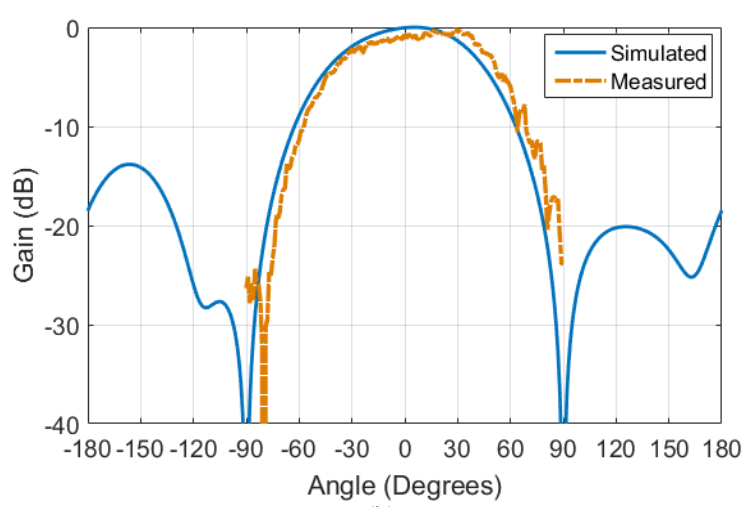

(b)

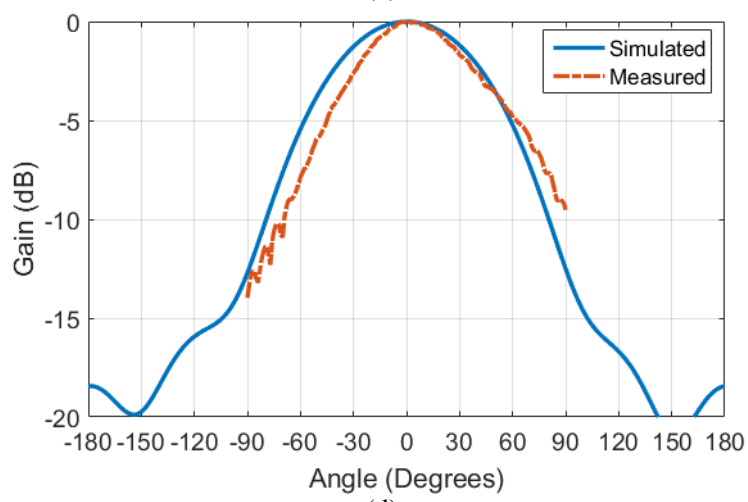

(d)

Fig. 19. Measured and simulated radiation patterns (a) H-plane $24 \mathrm{GHz}$, (b) H-plane $40 \mathrm{GHz}$ (c) E-plane $24 \mathrm{GHz}$, (d) E-plane $40 \mathrm{GHz}$.

tools, and chip fabrication, as well as Mr. Jules Gauthier of the Poly-Grames Research Center for his help in measurements.

\section{REFERENCES}

[1] C. Koverman, "Next-Generation Connected Support in the Age of IoT: It's time to get proactive about customer support," IEEE Consumer Electronics Magazine, vol. 5, no. 1, pp. 69-73, Jan. 2016.

[2] V. Moreno, M. A. Zamora and A. F. Skarmeta, "A Low-Cost Indoor Localization System for Energy Sustainability in Smart Buildings," IEEE Sensors Journal, vol. 16, no. 9, pp. 3246-3262, May, 2016.

[3] K. Wu, P. Burasa, T. Djerafi, and N. Constantin, "Millimeter-wave identification for future sensing, tracking, positioning and communicating systems," IEEE Millimeter waves (GSMM) Global Symp. \& ESA workshop on millimeter-wave technique. and applications, Espoo, Finland, June 6-8, 2016.

[4] P. Pursula, T. Vähä-Heikkilä, A. Müller, D. Neculoiu, G. Konstantinidis, A. Oja, and J. Tuovinen, "Millimeter-Wave Identification, A New ShortRange Radio System for Low-Power High Data-Rate Applications," IEEE Trans. Microw. Theory Techn., vol. 56, no. 10, pp. 2221-2228, Oct. 2008.

[5] S. Pellerano, J. Alvarado, and Y. Palaskas, "A mm-wave power harvesting RFID tag in $90 \mathrm{~nm}$ CMOS," IEEE J. Solid-State Circuits, vol. 45, no. 8, pp. 1627-1637, Aug. 2010.

[6] P. Pursula, F. Donzelli, and H. Seppä, "Passive RFID at MillimeterWaves," IEEE Trans. Microw. Theory Techn., vol. 59, no. 8, pp. 21512157, Aug. 2011.

[7] T. Djerafi, K. Wu, A. Marque, and A. Ghiotto, "Chipless substrate waveguide tag for millimeter wave identification," IEEE Millimeter waves (GSMM) Global Symp., Montreal, QC, Canada, May 25-27, 2015.

[8] P. Burasa, T. Djerafi, N. G. Constantin, and K. Wu, "High-Data-Rate Single-Chip Battery-Free Active Millimeter-Wave Identification Tag in 65-nm CMOS Technology," IEEE Trans. Microw. Theory Techn., vol. 64, no.7, pp.2294-2303, Jul. 2016.
[9] P. Burasa, N. G. Constantin, and K. Wu, "High-Efficiency Wideband Rectifier for Single-Chip Batteryless Active Millimeter-Wave Identification (MMID) Tag in 65-nm Bulk CMOS Technology," IEEE Trans. Microw. Theory Techn., vol. 62, no. 4, pp. 1005-1011, Apr. 2014.

[10] P. Burasa, N. G. Constantin, and K. Wu, "Low-Power Injection-Locked Zero-IF Self-Oscillating Mixer for High Gbit/s Data-Rate Battery-Free Active $\mu$ RFID Tag at Millimeter-Wave Frequencies in 65-nm CMOS," IEEE Trans. Microw. Theory Techn., vol. 64, no. 4, pp. 1055-1065, Apr. 2016.

[11] T. Maeda et al., "A Low-Power Dual-Band Triple-Mode WLAN CMOS Transceiver," IEEE J. Solid-State Circuits, vol. 41, no. 11, pp. 24812490, Nov. 2006.

[12] M. Zargari et al., "A Single-Chip Dual-Band Tri-Mode CMOS Transceiver for IEEE $802.11 \mathrm{a} / \mathrm{b} / \mathrm{g}$ Wireless LAN," IEEE J. Solid-State Circuits, vol. 39, no. 12, pp. 2239-2249, Dec. 2004.

[13] H. K. Chiou and I. S. Chen, "High-Efficiency Dual-Band On-Chip Rectenna for 35- and 94-GHz Wireless Power Transmission in 0.13CMOS Technology," IEEE Trans. Microw. Theory Techn., vol. 58, no. 12, pp. 3598-3606, Dec. 2010.

[14] Jie-Huang Huang, Jin-Wei Wu, Yi-Lin Chiou and C. F. Jou, "A $24 / 60 \mathrm{GHz}$ dual-band millimeter-wave on-chip monopole antenna fabricated with a $0.13-\mu \mathrm{m}$ CMOS technology," Antenna Technology, 2009. iWAT 2009. IEEE International Workshop, Santa Monica, CA, 2009, pp. 1-4.

[15] Chih-Ying Lin, Yo-Sheng Lin, Hsin-Chia Lu, Yi-Long Chang, "Design and implementation of A 24-/60-GHz dual-band monopole meander-line planar CMOS antenna," Microwave and Optical Technology Letters, vol. 54, pp. 1731-1737, 2012.

[16] G. Chi, B. Li and D. Qi, "A dual-frequency antenna fed by CPW," Proc. IEEE Antennas Propag. Soc. Int. Symp., pp. 459-462, 2005

[17] Horng-Dean Chen and Hong-Twu Chen, "A CPW-fed dual-frequency monopole antenna," IEEE Trans. Antennas Propag., vol. 52, no. 4, pp. 978-982, April 2004.

[18] Jin-Sen Chen, "Dual-frequency annular-ring slot antennas fed by CPW feed and microstrip line feed," IEEE Trans. Antennas Propag., vol. 53, no. 1 , pp. 569-573, Jan. 2005. 
[19] G. C Wang and J. D. Xu, "Novel application of CPW in antenna design for dual-frequency operation," Progress in Electromagn. Research Symp., Cambridge, USA, July 5-8, 2010.

[20] A.-P. Saghati, J.-S. Batra, J. Kameoka and K. Entesari, "Miniature and reconfigurable $\mathrm{CPW}$ folded slot antennas employing liquid-metal capacitive loading," IEEE Trans. Antennas Propag., vol. 63, no. 9, pp. 3798-3807, Sept. 2015.

[21] J. Xu, Z. -N. Chen and X. Qing, "CPW center-fed single-layer SIW slot antenna array for automotive radars," IEEE Trans. Antennas Propag., vol. 62, no. 9, pp. 4528-4536, Sept. 2014.

[22] A. Mehdipour, K. M. Aghdam, R. Faraji-Dana and M. Kashani-Khatib, "A novel coplanar waveguide-fed slot antenna for ultrawideband applications," IEEE Trans. Antennas Propag., vol. 56, no. 12, pp. 38573862, Dec. 2008.

[23] W.-S. Chen and K.-L. Wong, "Dual-frequency operation of a coplanar waveguide-fed dual-slot loop antenna," Microw. Opt. Technol. Lett., vol. 30, pp. 38-40, Jul. 2001.

[24] P. Shiji and C. Filippo, "Design of a CMOS on-chip slot antenna with extremely flat cavity at $140 \mathrm{GHz}, "$ IEEE Antennas Wireless Propag. Lett., vol. 10, pp. 827-830, Jul. 2011.

[25] B. Adel et al., "Back radiation reduction of $60 \mathrm{GHz}$ CMOS slot antennaon-chip (AoC) using artificial dielectric layer (ADL) for area reuse," Radio Science Meeting Joint AP-S Symp., Memphis, TN, July 6-11, 2014.

[26] Guo Qing Luo, Lin Qi Wu, and Xiao Hong Zhang, "An AMC Backed Folded Dipole Slot Antenna Based on CMOS Process," International Journal Antennas Propag., vol. 2013, Article ID 351956, 4 pages, 2013.

[27] J. Coonrod, B. Rautio, "Comparing Microstrip and CPW Performance," Microwave Journal, Jul. 2012.

[28] D. Titz, F. B. Abdeljelil, S. Jan, F. Ferrero, C. Luxery, P. Brachat and G. Jacquemod, "Design and characterization of CMOS on-chip antennas for $60 \mathrm{GHz}$ communications," Radio-engineering Journal, vol. 21, no. 1, pp. 324-331, Apr. 2012.

[29] D. Hou, Y. Z. Xiong, W. L. Goh, S. Hu, W. Hong and M. Madihian, "130-GHz On-Chip Meander Slot Antennas with Stacked Dielectric Resonators in Standard CMOS Technology," IEEE Trans. Antennas Propag., vol. 60, no. 9, pp. 4102-4109, Sept. 2012.

[30] A. Babakhani, X. Guan, A. Komijani, A. Natarajan and A. Hajimiri, "A 77-GHz Phased-Array Transceiver With On-Chip Antennas in Silicon: Receiver and Antennas," in IEEE Journal of Solid-State Circuits, vol. 41, no. 12, pp. 2795-2806, Dec. 2006.

[31] Chen, H. M., Wang, Y. K., Lin, Y. F., Lin, S. C., \& Pan, S. C. (2009). A compact dual-band dielectric resonator antenna using a parasitic slot. IEEE Antennas and Wireless Propagation Letters, 8, 173-176.

[32] Liu, H., Liu, Y., Wei, M., \& Gong, S. (2015, July). A novel dualbroadband dielectric resonator antenna based on modified Sierpinski fractal geometry. In Antennas and Propagation \& USNC/URSI National Radio Science Meeting, 2015 IEEE International Symposium on (pp. 4344).

[33] Ding, Y., \& Leung, K. W. (2009). On the dual-band DRA-slot hybrid antenna. IEEE Transactions on Antennas and Propagation, 57(3), 624630.

[34] R. Kranenburg, S. A. Long and J. T. Williams, "Coplanar Waveguide Excitation of Dielectric- Resonator Antennas," IEEE Trans. Antennas Propag., vol. 39, no. 1, pp. 119-122, Jan. 1991.

[35] T. H. Chang and J. F. Kiang, "Dual-band split dielectric resonator antenna," IEEE Trans. Antennas Propag., vol. 55, no. 11, pp. $3155-$ 3162, Nov. 2007.

[36] A. Buerkle, K. Sarabandiand and H. Mosallaei, "Compact slot and dielectric resonator antenna with dual-resonance, broadband characteristics," IEEE Trans. Antennas Propag., vol. 53, no. 3, pp. 10201027, Marc. 2005.

[37] S. Hauptmann, M. Hellfeld, C. Knochenhauer, and F. Ellinger, "Modeling bond wires for millimeter wave rfic design," IEEE Int. Microw. Commun. Antennas Electron. Syst. Conf., pp. 1-4, 2009.

[38] D. Jahn, R. Reuter, Y. Yin, and J. Feige, "Characterization and modeling of wire bond interconnects up to $100 \mathrm{GHz}$," IEEE Comp., Semicond. Integr. Circuits Symp., San Antonio, pp. 111-114, 2006.

[39] J. Lee, Y. Chen, and Y. Huang, "A low-power low-cost fully-integrated 60-ghz transceiver system with ook modulation and on-board antenna assembly," IEEE J. Solid-State Circuits, vol. 45, no. 2, pp. 264-275, Feb. 2010.

[40] B. Klein, M. Jenning, P. Seiler, K. Wolf, D. Plettemeier, "Verification and Demonstration up to $67 \mathrm{GHz}$ of an On-Chip Antenna Pattern
Measurement Setup," IEEE Antenna Measurements \& Applications (CAMA) Conf., pp. 1-4, Nov. 2014.

[41] C. Hannachi, S. O. Tatu, "A New Compact V-band Six-port DownConverter Receiver for High Data Rate Wireless Applications," IEEE Topical Conference on Wireless Sensors and Sensor Networks (WiSNet), pp. 26-28, San Diego, CA, USA, 25 - 28 January 2015. 